\title{
Approach of design influence on air flow rate through the heat exchangers
}

Ricardo de Oliveira Silva ${ }^{1}$, Thaís Piva de Castro $^{2}$, Paulo Marcel Alves Bandeira ${ }^{1}$, Diego Erberelli $^{3}$, Carlos Teófilo Salinas Sedano ${ }^{4}$

${ }^{1}$ Volkswagen do Brasil Indústria de Veículos Automotores Ltda.

${ }^{2}$ Engbras Software e Projetos Ltda.

${ }^{3}$ MAHLE Behr Gerenciamento Térmico Brasil Ltda.

${ }^{4}$ UNICAMP

E-mails: $\quad$ ricardo.silva@volkswagen.com.br, thais.castro@engbras.com.br paulo.bandeira2@volkswagen.com.br, diego.erberelli@br.mahle.com, salinas@fem.unicamp.br

\begin{abstract}
The heat exchangers are responsible by the thermal equilibrium in an internal combustion engine, but it is important to emphasize, that this property is directly influenced by the air mass flow rate which passes through heat exchanger, given a specific coolant flux and heat exchanger geometry. The present work aims to show the influence of vehicle components, such as air deflectors, fan, radiator's shroud, grilles and gaskets on air mass flow rate passing through the heat exchangers and their consequences on ITD (Inlet Difference Temperature) estimation. This influence was quantified using CFD (Computational Fluid Dynamics) and 1-D simulation analysis of vehicle under-hood. The simulations were performed in top speed condition of the vehicle, which characterizes full throttle of the engine and $50 \mathrm{~kW}$ of rejected heat. The analysis allows to state that an increment of air flux was possible reducing leakage and redirecting the air flux.
\end{abstract}

\section{Introduction}

A model of vehicle can show different versions, simply making changes of radius of the wheels, types of tires, set of grilles and bumpers, hoods and headlights, for example. These changes can define versions of luxury, sportive, family, off-roader or an economy car. Furthermore it is important to highlight the possibility of different setups of powertrain, so that each one of these configurations has significant influence on thermal management of the vehicle and its employment in a specific climate zone (hot and temperate lands).

Such premises of operation require some care of sizing of the cooling package. For a better practice of sizing, it is recommended to use CAE resources like CFD and 1D analysis, whenever component like radiators, condensers, fans, shrouds, air flow deflectors, thermostatic valves, expansion tanks and gaskets are been chosen.

The applicability of the simulation (CFD) allows forecasting the quantity of air mass flow rate which passes through the radiator, one of the variables in the formula of the heat gained by the air which can be expressed as:

$\dot{Q}_{a}=\dot{m}_{a} \cdot c_{p a} \cdot\left(T_{a i}-T_{a o}\right)$

Eq. 01 
Where:

$\dot{Q}_{a}=$ Overall heat transfer of the air (kW);

$\dot{m}_{a}=$ air mass flow rate $(\mathrm{kg} / \mathrm{s})$;

$c_{p a}=$ Specific heat capacity of the air $(\mathrm{kJ} / \mathrm{kg} \cdot \mathrm{K})$;

$T_{a i}=$ Temperature of the air inlet $(\mathrm{K})$;

$T_{a o}=$ Temperature of the air outlet $(\mathrm{K})$;

The performance of a heat exchanger can be determined by examining the heat loss and gain that takes place between its working fluids:

The lost by the coolant can be expressed as:

$\dot{Q}_{c}=\dot{m}_{c} \cdot c_{p c} \cdot\left(T_{c i}-T_{c o}\right)$

Where:

$\dot{Q}_{c}=$ Overall heat transfer of the coolant $(\mathrm{kW})$;

$\dot{m}_{c}=$ coolant mass flow rate $(\mathrm{kg} / \mathrm{s})$;

$c_{p c}=$ Specific heat capacity $(\mathrm{kJ} / \mathrm{kg} . \mathrm{K})$

$T_{c i}=$ Temperature of the coolant inlet $(\mathrm{K})$;

$T_{c o}=$ Temperature of the coolant outlet $(\mathrm{K})$;

The heat loss and gain are calculated by software which uses the concept of block's diagram (1-D simulation).

This software uses the following input data:

a) coolant pump map;

b) fan map;

c) the lift curve of the thermostatic valve;

d) the map of rejected heat by the engine in different conditions of operation (engine speed, torque and power);

e) the geometry of the hoses;

f) the curves of backpressure of the engine jacket;

g) the curves of backpressure of the radiator (air side);

h) the curves of backpressure of the radiator (coolant side);

i) condenser parameters, similar of the radiator;

The 1-D simulation makes a compilation of these data searching or estimating the point of working of the vehicle.

The parameter ITD is defined by $\varepsilon$-NTU method of sizing of the heat exchangers which can be expressed by:

$\dot{Q}=\varepsilon . C \min . I T D$

$\dot{Q}=\varepsilon . C \min .\left(T_{c i}-T_{a i}\right)$

Where:

$\varepsilon=$ effectiveness;

$C \min =$ The smaller capacity rate between air and coolant.

$C_{c}=\dot{m}_{c} \cdot c_{p c}$

$C_{a}=m_{a} \cdot c_{p a}$

Where:

$C_{c}=$ Capacity rate of the coolant side;

$C_{c}=$ Capacity rate of the air side. 
The effectiveness is given by:

$$
\begin{aligned}
& \varepsilon=\frac{\dot{Q}}{\dot{Q}_{\max }} \\
& \dot{Q}_{\max }=C \min .\left(T_{c i}-T_{a i}\right)
\end{aligned}
$$

Where $\dot{Q}_{\max }$ is the maximum quantity of heat transfer possible.

The parameter of ITD is usually employed to specify if a vehicle and its cooling system is able to be used in a determinate condition. For top speed condition for example with $45{ }^{\circ} \mathrm{C}$ of ambient temperature and $30 \%$ of relative humidity, the recommended value of ITD is $75 \mathrm{~K}$.

More details of $\varepsilon$-NTU method can be seen in Kanefsky et al. (1999).

The reduction of engineering costs using simulation is widely proved and represents more one attractive point for its application, mainly during the phase of development avoiding costs of experimental tests and prototypes.

\section{Underhood simulation for cooling system}

\subsection{CFD simulation}

In principle it is necessary to know what vehicle (model and version) will be simulated and the condition which the vehicle will be studied. In our example it is been studied a vehicle in top-speed $\left(185 \mathrm{~km} / \mathrm{h}\right.$, with $45^{\circ} \mathrm{C}$ and $40 \%$ of relative humidity).

After, it is prepared the geometry of the vehicle, in order to have a representative virtual model.

In this phase of the process of simulation, the geometry imported from CAD, (independently of the software of CAD) are inappropriate for CFD simulation.

In some case these geometric problems are increased when the model are exported using ".stl" file extension.

Normally these geometries show the following type of surface problems which can be repaired manually by the own software of CFD:

- Free edges.

- Zip edges or fill holes with new triangles.

- Intersecting surfaces.

- Intersect then delete surfaces.

- Imprint surfaces and edges onto target surfaces/bodies.

- Surfaces can be split and combined to create required boundaries.

The process to clean a surface could expend a lot of time, if this procedure is usually performed manually, therefore it is recommended to use some resources to repair surface which is available in the package of the software. The software used for the proposed simulation is the Star CCM+ which has a resource called wrapping.

The wrapping tool tries to solve every problem found among the cells of the virtual model.

In the fig. 1, extracted from Mouffouk (2014), it is possible to notice the difference between surfaces after and before the process of wrapping.

Each one of the components of the vehicle receives a specific setup of surface mesh condition, with a specific surface size. 
This procedure is adopted just for the surficial mesh of the vehicle which solves mainly problems such as:

- Pierced faces;

- Free edges;

- Non-manifold edges;

- Non-manifold vertices.

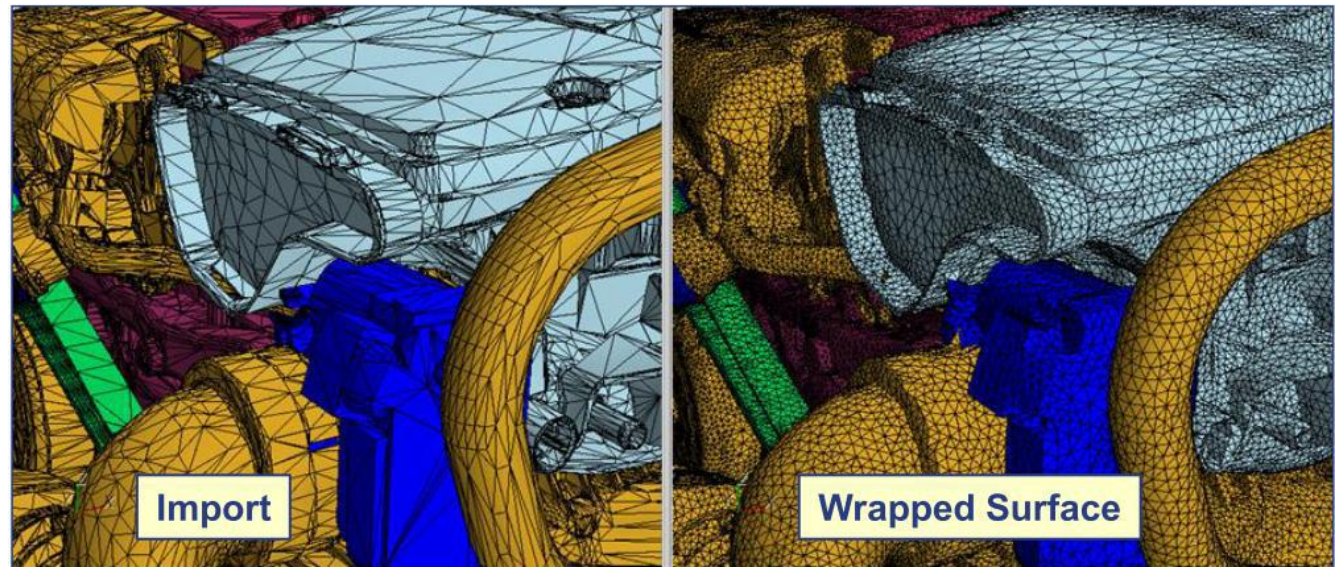

Figure 1 - The difference between the imported CAD surface after wrapper and before the wrapper [6].

The next step is to prepare virtual wind tunnel where the wrapped surface of the vehicle will be placed. In other to avoid the influence of the tunnel on the airflow, it is adopted the dimensions of the wind tunnel indicated in the fig. 2.

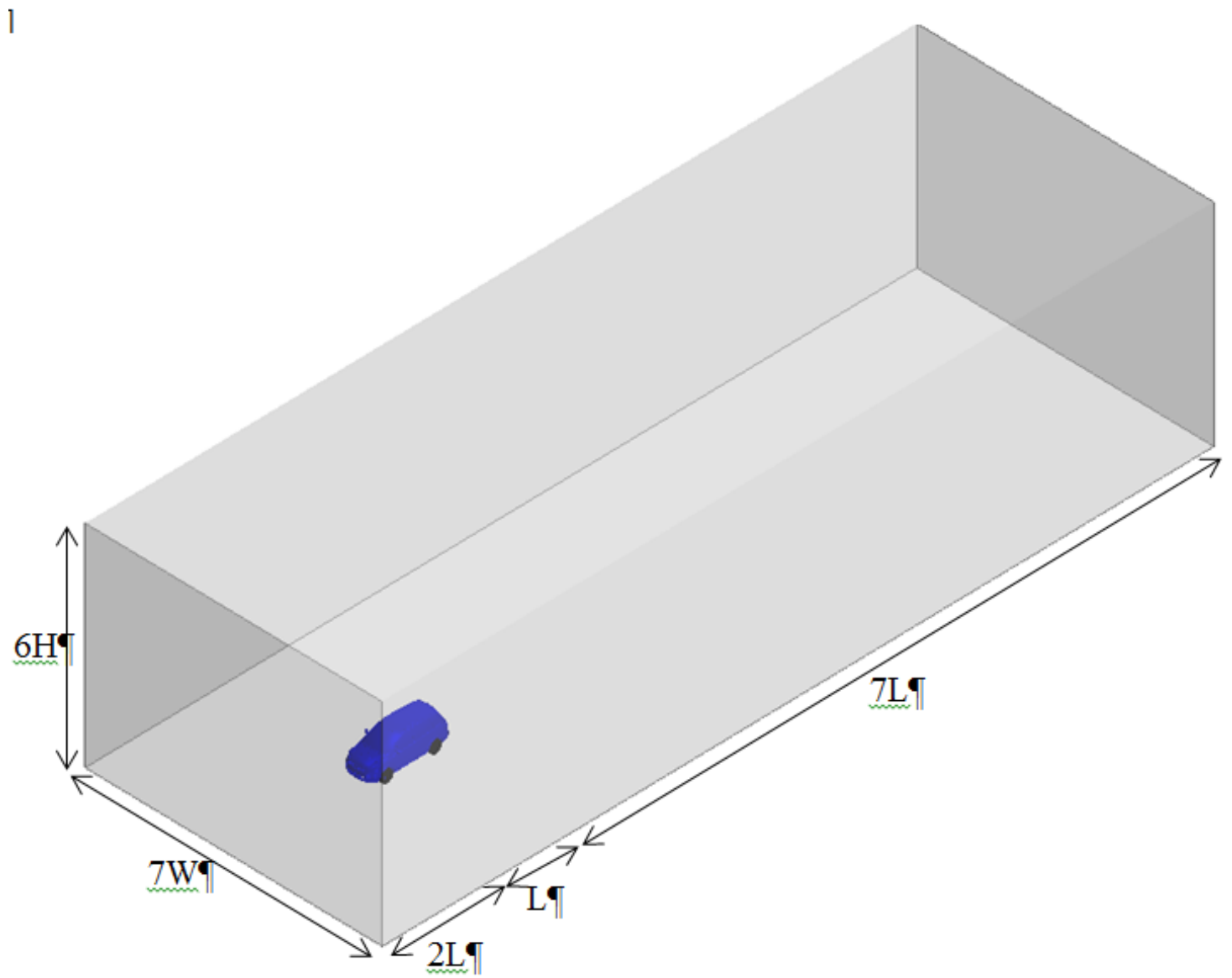


Figure 2 - Dimension of the virtual wind tunnel.

It is recommended to take care with the distance between the floor of the vehicle and the ground of the wind tunnel.

Part of the tires should be removed, giving the effect to mold the tire on the ground. This effect is obtained making a subtraction between the vehicle and the wind tunnel. In the fig. 3 , it is possible to observe this effect.

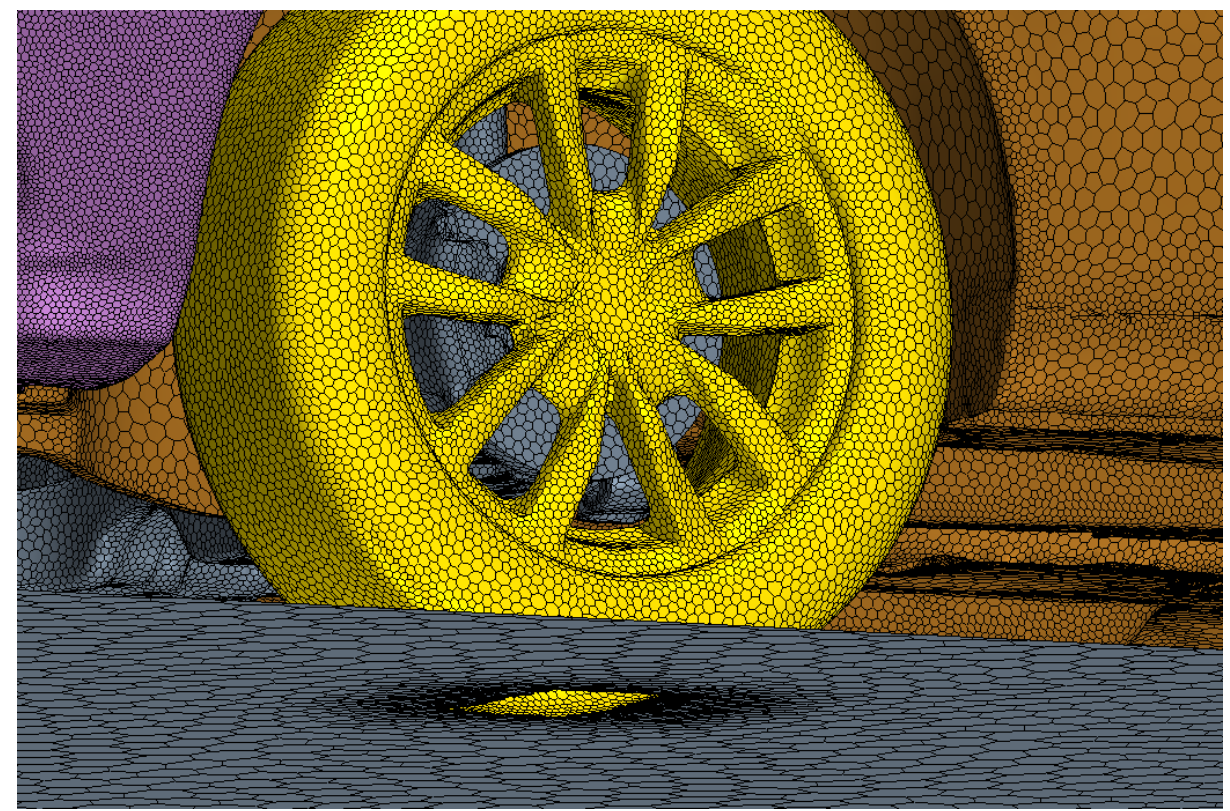

Fig. 3 - Subtraction between the tire and the wind tunnel ground

The same command subtract is used to insert the radiators and the condenser (porous medium) in the wrapped surface of the vehicle.

This procedure is adopted in order to avoid deformation of the heat exchangers geometry during the process of wrapping which could generate error during the phase of volumetric mesh generation.

In the fig. 4 , it is possible to see the wind tunnel with the heat exchangers

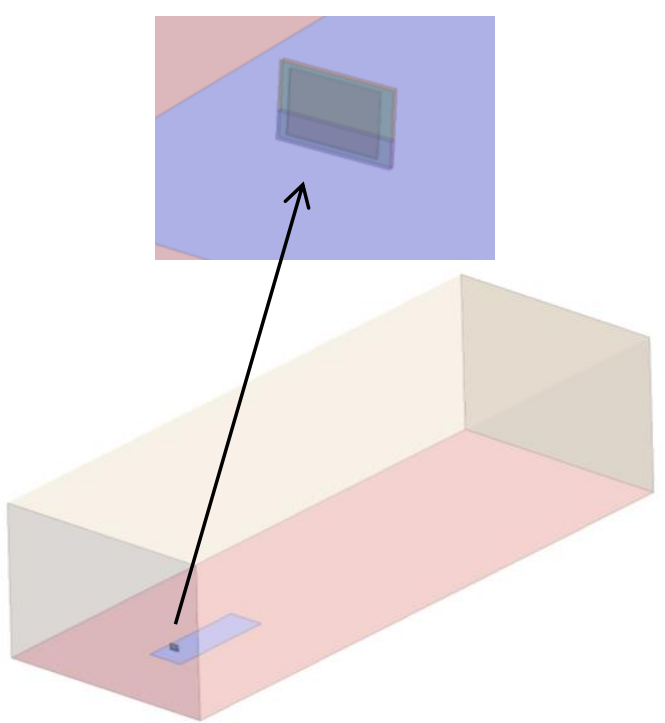

Figure 4 - Heat Exchangers in the tunnel. 
The fan interface is other important point to take care. Two surfaces are created in order to represent the difference of pressure between the upstream and downstream.

The distance between these surfaces is $0.1 \mathrm{~mm}$ and during the process of wrapping an initial interface is created (using command repeating). During the process to generate a volumetric mesh the same setup is kept.

The fig. 5 shows the model of the fan; in the end of the process of volumetric mesh the surfaces upstream and downstream are jointed.

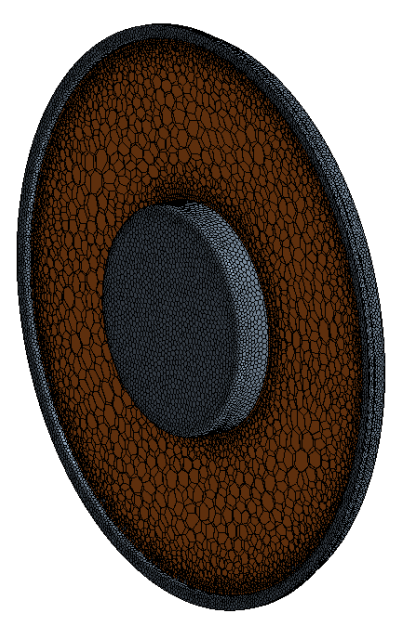

Figure 5 - Fan model

The setup of the wind tunnel should consider indicating the walls inlet, outlet, the floor velocity and the prismatic layer (boundary layer)

It is indicating in the fig. 6 the mainly configuration of the wind tunnel.

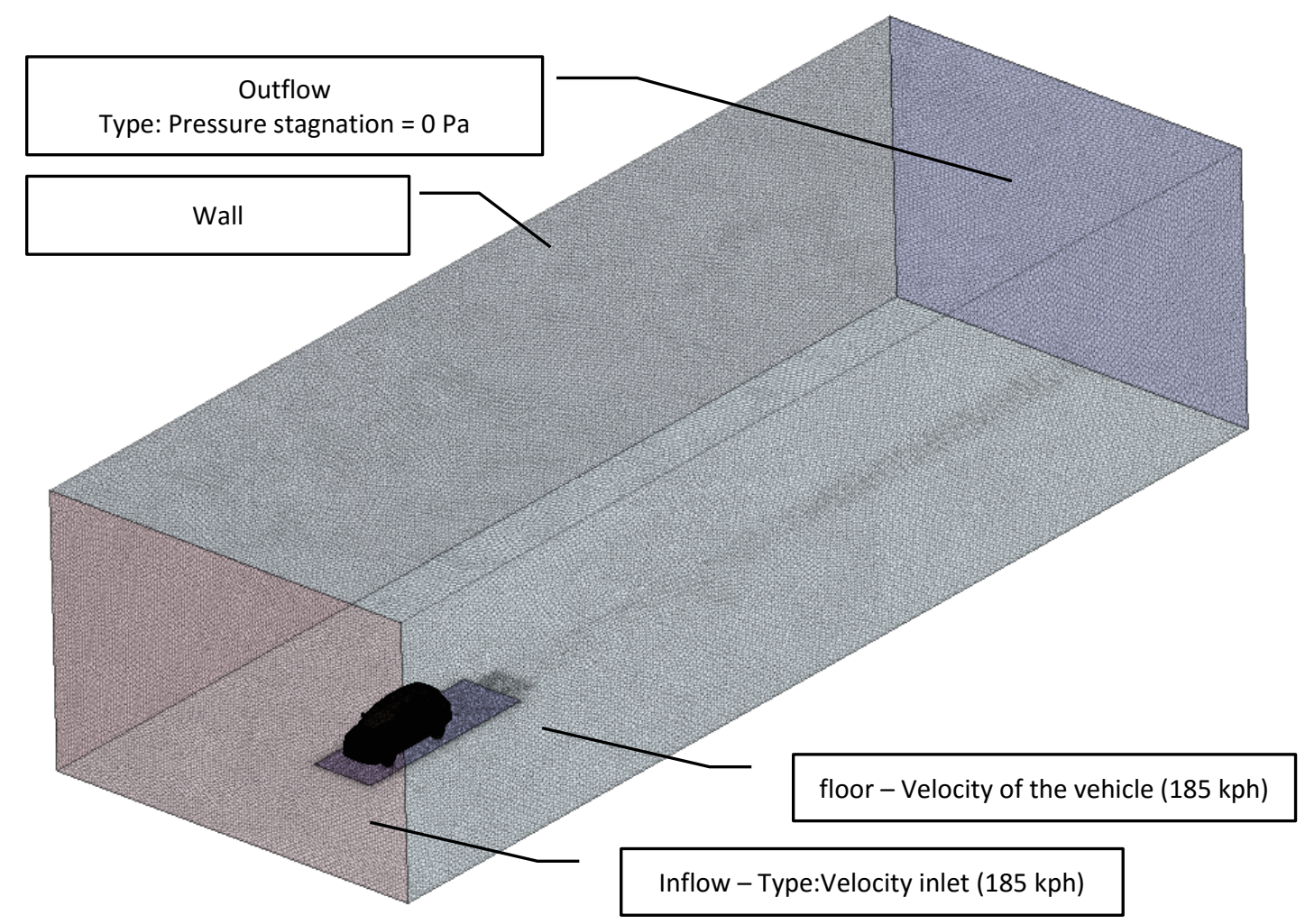

Figure 5 - Wind Tunnel 
The prismatic layer could follow what it is recommended by Mouffouk (2014): "For wall functions, each wall-adjacent cell's centroid should be located within the loglaw layer, $\left(30<\mathrm{y}^{+}<300\right)$. A $\mathrm{y}^{+}$value close to the lower bound $\mathrm{y}^{+}=30$ is most desirable".

The volumetric mesh is performed using a tool called remeshing, with polyhedral configuration; the wrapped surface is reworked before this process.

The present flow field is mathematically described by continuity and the incompressibility via Reynolds Average Navier Stokes (RANS) equations. To predict complex turbulent flow was adopted Realizable K- $\varepsilon$ turbulence model and High-Re wall treatment.

For this simulation, the space discretization can be seen in the fig. 6. It was utilized a polyhedral mesh with approximately 17 million of cells.

In order to increase the accuracy and reduce error during the processing, some volume of the domain is refined reducing the size of the cells.

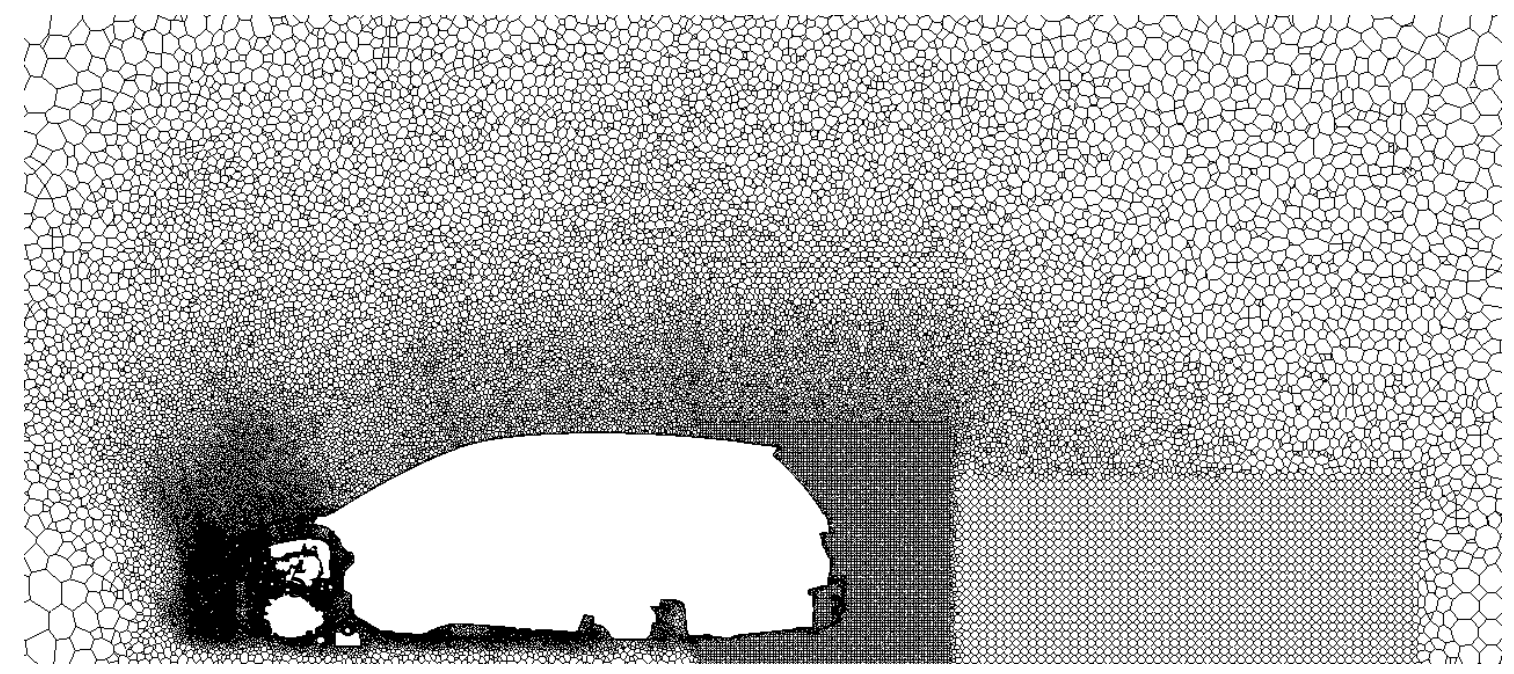

Figure 6 - Volumetric mesh

It is desirable to represent the intake airflow of the air filter and the exhaust gases in the tail pipe, in both case it is possible to represent a datum plan as an inflow for intake system and an outflow for the exhaust system.

The values of these mass flow rates depend on the engine condition. In top speed these values represents full throttle of the engine.

\subsection{CFD setup}

The setup of the heat exchangers obeys the equation of Darcy (Eq. 04), for porous inertial resistance $\left(P_{i}\right)$ and for porous viscous resistance $\left(P_{v}\right)$.

$$
\frac{d p}{d x}=-\left(P_{i} v^{2}+P_{v} v\right)
$$

Where:

$d p$ - Differential of pressure between upstream and downstream;

$d x$ - Differential of thickness of the porous medium;

$v$ - Velocity of the fluid. 
The components of Darcy's equation are input in the software and it has been shown satisfactory results.

The characteristic curve of the fan that it is given by the relation $(\mathrm{dp} / \mathrm{dv})$, where $d p$ is the difference of pressure and $d v$ is difference of velocity. It generates a polynomial function of $2^{\text {nd }}$ degree, that is shown in the fig. 7.

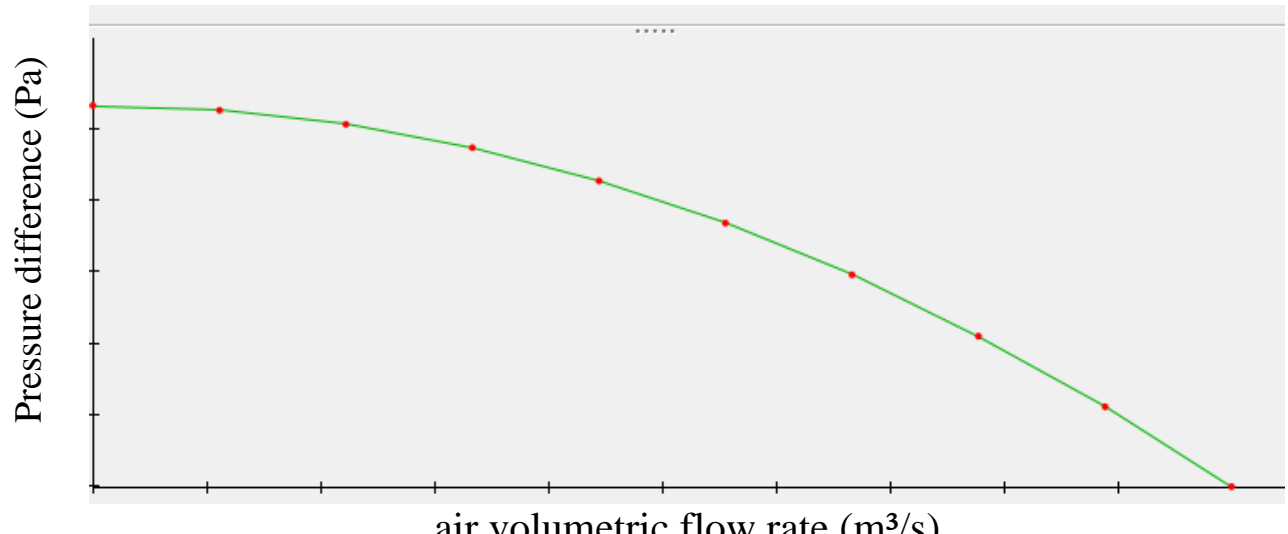

Figure 7 - Characteristic curve of the fan

The surfaces of the fan (upstream and downstream) should be put in rotation. suppliers.

For both cases (heat exchangers and fan) the values are obtained by the

The summary of the boundary conditions used in the flow field characteristics could be seen in the table 1 .

Table 1: Boundary conditions used for CFD simulations of the wind tunnel

\begin{tabular}{ccc}
\hline Boundary type & Specific condition & Valor \\
\hline Velocity inlet & Velocity magnitude & $185.1 \mathrm{~km} / \mathrm{h}$ \\
& Turbulent intensity & 0.01 \\
& Turbulent viscosity ratio & 10 \\
Pressure outlet & Atmospheric pressure & $101325 \mathrm{~Pa}$ \\
Floor (Wall) & Relative velocity & $185.1 \mathrm{~km} / \mathrm{h}$ \\
\hline
\end{tabular}

The air dynamic viscosity was defined constant and value of $1.85 * 10 \mathrm{e}^{-5} \mathrm{~Pa}-\mathrm{s}$. For the density of reference were adopted $1.18 \mathrm{~kg} / \mathrm{m}^{3}$.

\subsection{1 -D Analysis}

Basically the 1-D analysis follows the scheme shown in the fig. 8 below.

The characteristic's maps of the radiator are obtained by the supplier, similar information that it is used in CFD analysis, but in this case there is a map of heat exchange of the radiator.

The main information obtained via CFD is the air mass flow rate which is input in the software and it is able to estimate the values of ITD.

This analysis is able to obtain ITD data following the script shown in the introduction of the present work.

Although it was used simplified circuit of cooling, it is possible to increment the model, using all of possible variable that could influence the ITD estimation, as it could be seen in the fig.9. 


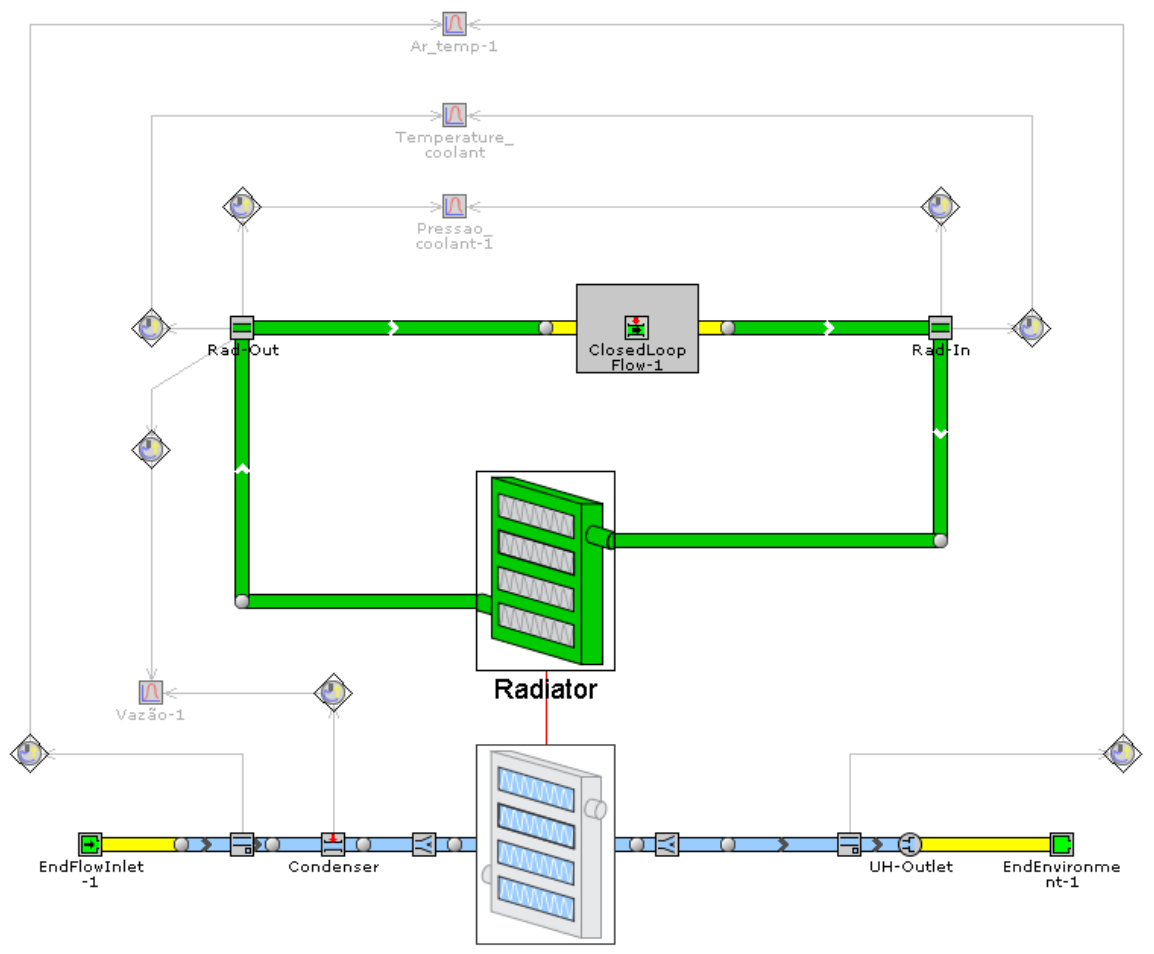

Figure 8 - Simplified scheme of 1-D analysis

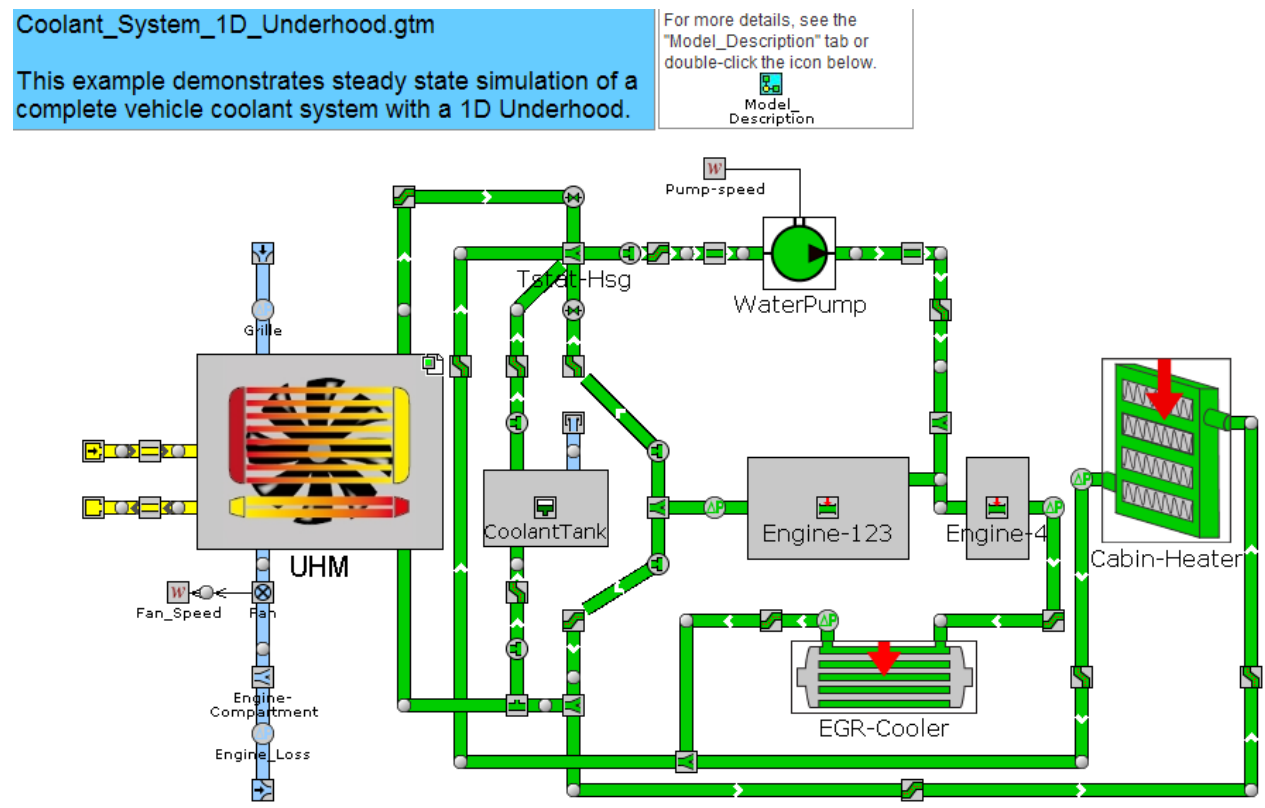

Figure 9 - Cooling System

\section{Air Deflectors analysis}

\subsection{Air mass flow rate estimation}

The overview of the procedures of the simulation is necessary to explain the methodology of calculation and how these results are obtained. 
The present case tends to show the influence of the air flow deflector in the air mass flow rate which passes through the heat exchangers.

Case \#1: The simulation was performed using air deflector as it is shown in the fig. 10 (a) and (b).

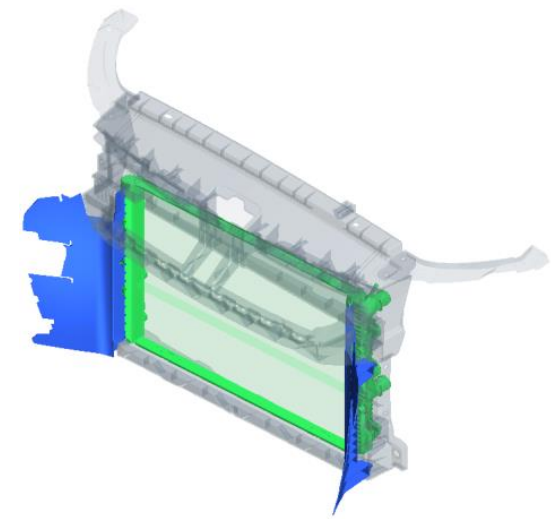

(a)

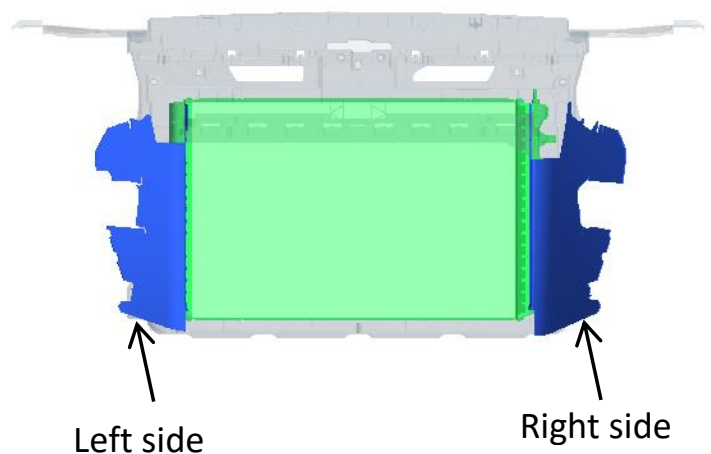

(b)

Figure 10 - Side air flow deflector in the front-end and radiator set: view (a) perspective; (b) front.

Case \#2: The case 2 as incremented an upper deflector, as it could be seen in the fig. 11 (a) and (b).

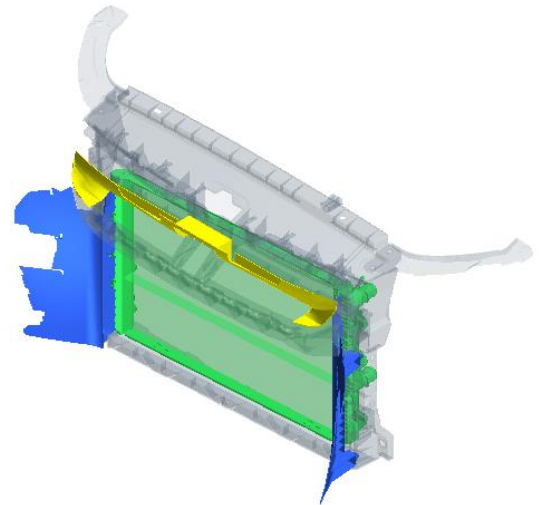

(a)

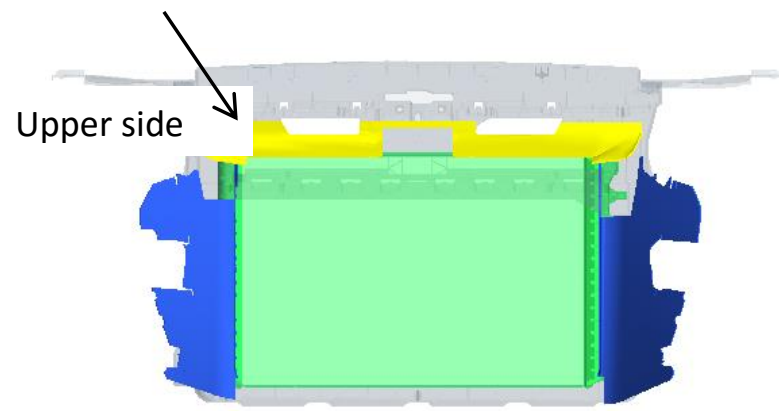

(b)

Figure 11 - Upper deflector.

Case \#3: In the $3^{\text {rd }}$ case was added a gasket between radiator and front-end (fig. 12).

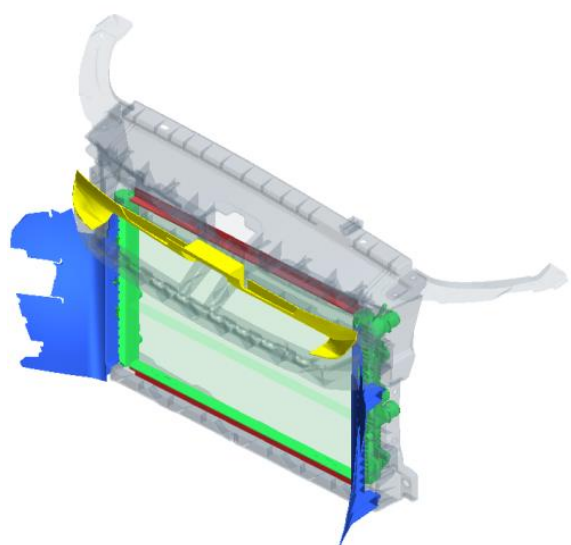

(a)

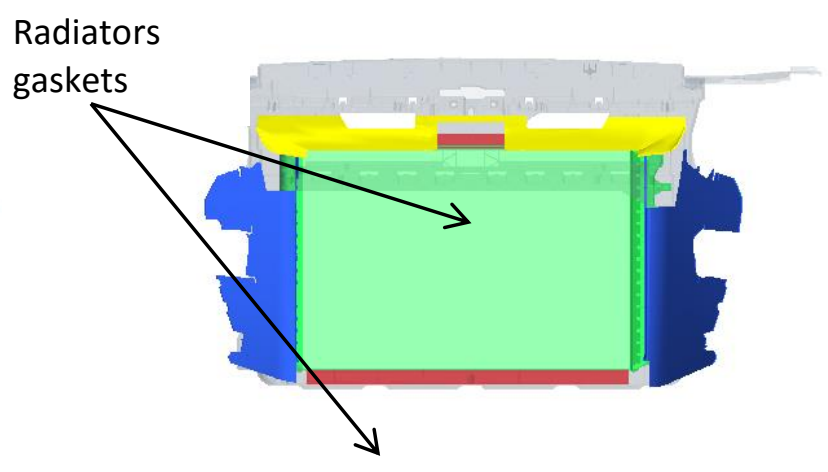

(b)

Figure 12 - Upper air flow deflector in the front-end and radiator set: view (a) perspective; (b) front. 
Case \#4: For this case a hood gasket was added fig. 13 (a) and (b).

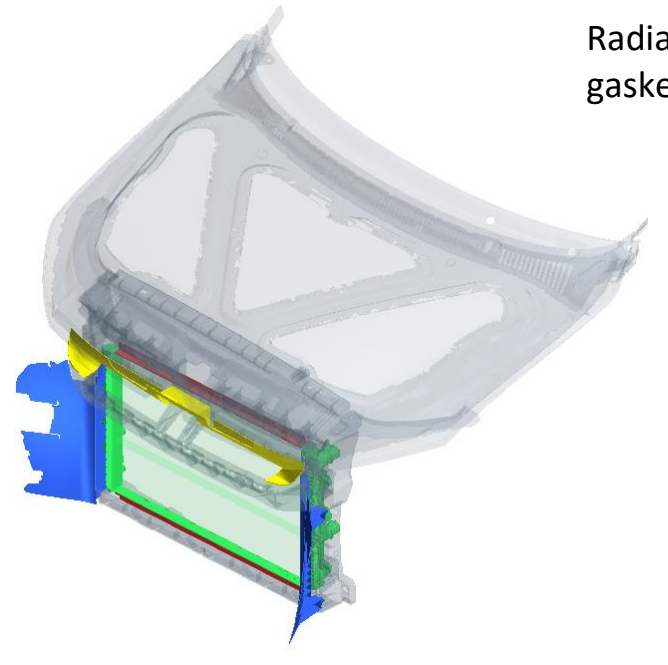

(a)

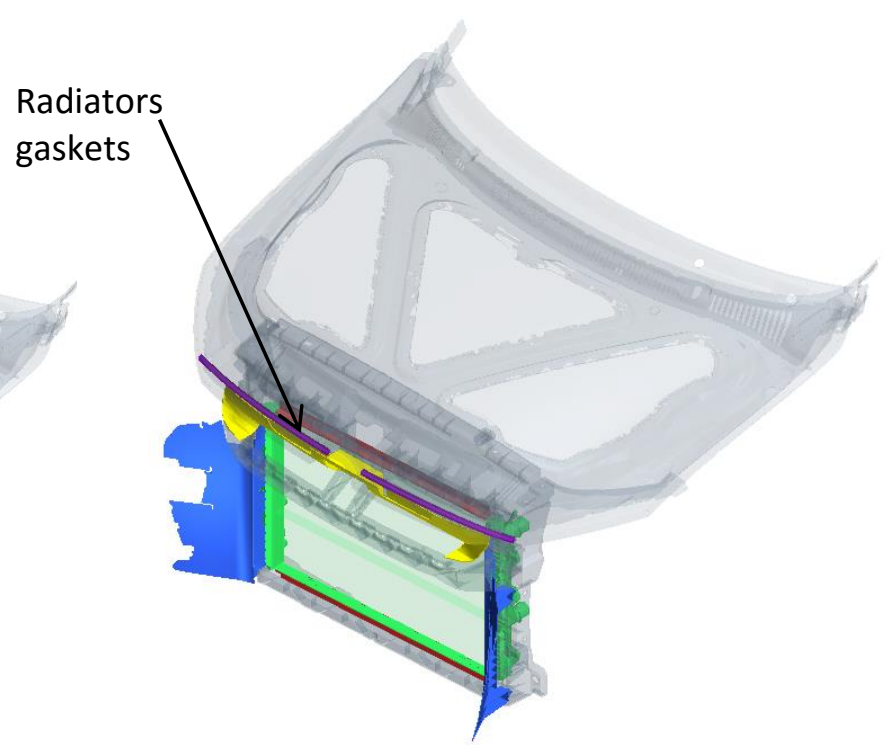

(b)

Figure 13 - Hood gaskets.

In the table 2, it is possible to observe the increment of air mass flow rate which passes through the radiator after each action shown for each case.

Table 2: Comparison of the Air Mass Flow Rate [kg/s]

\begin{tabular}{lcccc}
\hline & Case\#1 & Case\#2 & Case\#3 & Case\#4 \\
\hline Condenser & 1.2 & 1.19 & 1.19 & 1.22 \\
Main radiator & 0.97 & 1.02 & 1.05 & 1.10 \\
Aux radiator & 0.75 & 0.75 & 0.77 & 0.79 \\
Fan & 1.24 & 1.26 & 1.3 & 1.34 \\
\hline
\end{tabular}

Additionally it is shown the air flux through the fan and the condenser.

Our model has an auxiliary radiator used in an intercooler system, but the focus of ITD calculation is in the main radiator.

\subsection{ITD estimation}

Based on the results obtained in the table 2, it is estimated the value of ITD. In the Table 3, it is possible to see the reduction of ITD after each action shown in each case.

Table 3: Comparison of the ITD [K]

\begin{tabular}{lcccc}
\hline & Case\#1 & Case\#2 & Case\#3 & Case\#4 \\
\hline ITD & 64.61 & 64.09 & 62.71 & 60.59 \\
\hline
\end{tabular}




\section{Conclusion}

The values shown in the Table 4 are compiled in the fig. 14 . The values of ITD were reduced with the actions; it could be interesting when the analysis passes to consider the costs of the components like the radiator and a deflector.

In case of the values of ITD is on borderline of acceptable values, it is interesting to reduce the leakage of the air flow rate rather than to invest in a heat exchanger with more capacity of heat exchange of effectiveness.

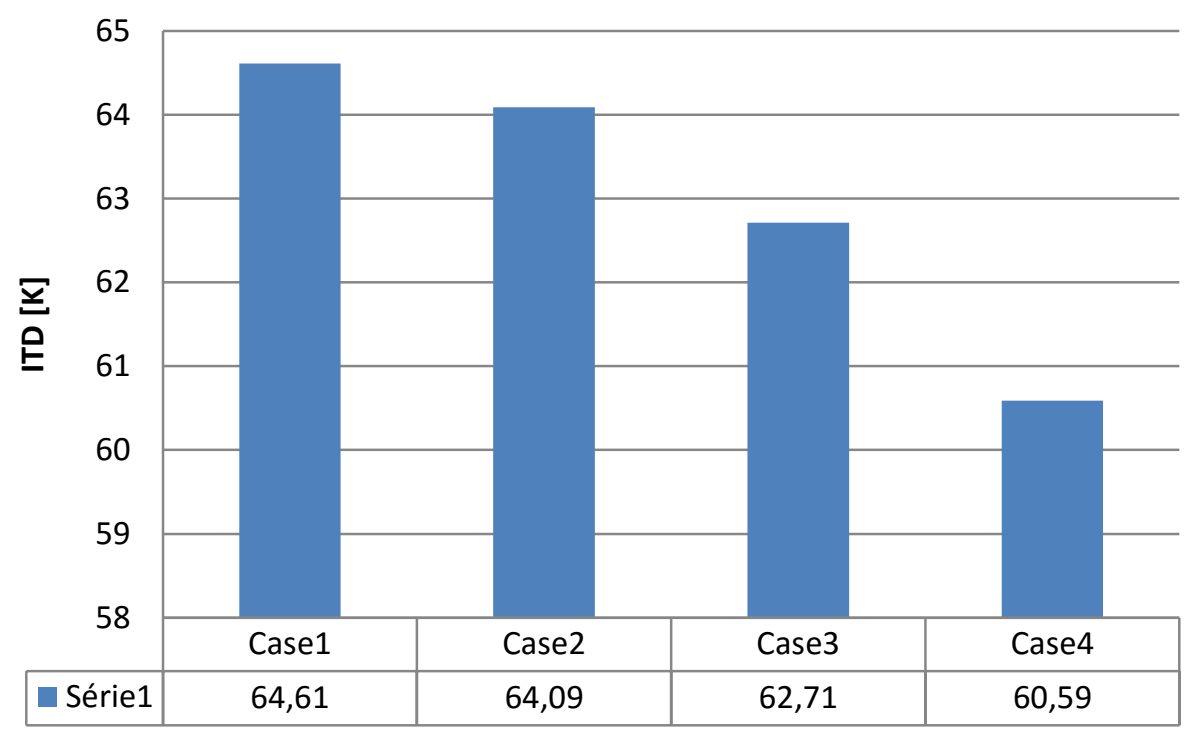

Figure 14 - ITD estimation

\section{References}

[1] Lisa L., Helena M. Aerodynamic Drag Reduction of a Heavy Truck with Variable Cooling Air Intake Area. Master's Thesis in the Master's programme Automotive Engineering. CHALMERS UNIVERSITY OF TECHNOLOGY - Department of Applied Mechanics-Division of Vehicle Safety. Göteborg, Sweden 2009.

[2] Abiodun Matthew Amao. Mathematical model for Darcy Forchheimer flow with applications to well performance analysis. Master of Science Thesis, Texas Tech University, August 2007.

[3] GILLESPIE, T. D. Fundamentals of Vehicle Dynamics. Warrendale, PA: Society if Automotive Engineers, Inc, 1992.

[4] Kanefsky P., Nelson V. A., Ranger M., A Systems Engineering Approach to Engine Cooling Design - The $44^{\text {th }}$ L. Ray Buckendale Lecture - SAE SP-1541.

[5] Quim N., Desenvolvimento de Uma Metodologia de Simulação Aplicada ao Sistema de Arrecimento Veicular - USP 2007. 
[6] Mouffouk, M. A., Aerodinnamic Development of the Seguracing F1-R01 Prototype Using CFD- University H.L of Batna Department of Mechanical Engineering Specialty Aeronautical Engineering- Batma/Alderia 2013/2014 